\title{
CREATING A HYPER-PLACE: HOW REFUGEE HELPERS CREATE A PLACE FOR THEIR VALUES
}

\author{
Johanna F. Gollnhofer
}

\begin{abstract}
Purpose - Research has shown that activist consumers create places that are imbued with idiosyncratic meanings, conventions, rules, and activities. However, research on why and how such places are created is scant.

Methodology/approach - This ethnography in the context of voluntary refugee helpers shows why and how a meaningful place is produced.

Findings - By drawing on spatial theory from human geography, I map out how activist consumers create a hyper-place: embedded in the dynamics of demarcating and linking, voluntary helpers set a place apart from the surrounding space and other places. This place allows for practices that combine materiality, activities, and meanings in new ways in comparison to practices in traditional places. This place allows for the enactment and the conveyance of values that are not accommodated in traditional marketplaces.
\end{abstract}

\footnotetext{
Consumer Culture Theory

Research in Consumer Behavior, Volume 18, 111-126

Copyright (C) 2017 by Emerald Group Publishing Limited

All rights of reproduction in any form reserved

ISSN: 0885-2111/doi:10.1108/S0885-211120160000018010
} 
Originality/value - I contribute to literature on activist consumers and the role of place within consumer research.

Keywords: Activist consumers; place; ethnography; consumer behavior

\section{INTRODUCTION}

If places are indeed a fundamental aspect of men's experience in the world, if they are sources of security and identity for individuals and for groups of people, then it is important that the means of experiencing, creating and maintaining significant places are not lost.

-Relph (1976, p. 6)

Recent research has mentioned the role of places within consumption studies (Albinsson \& Perera, 2012; Debenedetti, Oppewal, \& Arsel, 2014; Kozinets, 2002; O'Guinn \& Belk, 1989; Rosenbaum, 2006; Arsel, Debenedetti, \& Merigot, 2012). For instance, theme parks such as heritage villages provide a spatial setting for extraordinary consumption experiences (O'Guinn \& Belk, 1989). Not only marketers, but consumers too produce and create new places as they become increasingly activist (Albinsson \& Perera, 2012; Fournier, 1998; Klein, Smith, \& John, 2004). For instance, the Burning Man festival (Black Rock Desert, Nevada, United States), located in the middle of a dessert, serves as a playground for affluent Westerners that seek partial liberation from the marketplace and its rules, norms, and conventions (Kozinets, 2002). Other consumers come up with alternative markets that are subject to their idiosyncratic rules. For instance, Albinsson and Perera (2012) illustrate a consumer-initiated marketplace that is based on alternative rules of exchange (Albinsson \& Perera, 2012).

Prior research in consumer behavior often situates their studies in these contexts, but pushes the role and nature of these places to the background (Arsel et al., 2012; Sherry, 2000). This perspective is surprising as places - similar to ideologies or myths (Crockett \& Wallendorf, 2004; Luedicke, Thompson, \& Giesler, 2010) - are supposed to guide and shape our consumption, communication, and interaction behavior (Debenedetti et al., 2014).

By drawing on an ethnographic approach, this paper maps out why and how refugee helpers - a form of activist consumers - produce a meaningful place with its own boundaries and practices. I strive to answer the following research questions: 
- Why do activist consumers produce places?

- How do activist consumers produce places?

A spatial perspective adapted from the field of human geography helps us to illuminate and to present the findings. As the author is immersed in the investigated place since its inception, this paper is able to map out an emergent perspective on place creation.

\section{LITERATURE REVIEW: PLACES IN CONSUMPTION STUDIES}

By definition, a place is "a space, area, or spot that is set apart and used for a particular purpose" (http://dictionary.reference.com/browse/place). For instance, coffee houses (Karababa \& Ger, 2011), theme parks (O’Guinn \& Belk, 1989), Turkish squatters (Üstüner \& Holt, 2010), or eco-villages (Christian, 2003) are all places that are set apart from their surroundings. These places are subject to idiosyncratic rules, norms, and conventions. Transferring from one place to another goes hand in hand with new regulatory, normative, and cultural structures, and meanings and practices that are generally shared and upheld in the wider socio-geographical setting of that place vanish and are replaced by others that are specific to the new place.

Place matters in marketing as well as in consumer behavior. From a marketing perspective, the role of place is, for instance, reflected in the 4 Ps (product, price, place, promotion). From a consumer behavior perspective, since all consumption is spatially located place might be seen as an underlying structure that implicitly guides our consumption behavior (Sherry, 2000). Similar to myth (Luedicke et al., 2010) or ideology (Crockett \& Wallendorf, 2004), places inform our consumption decisions.

Although a few studies deal with the concept of place attachment and how an emotional bond between a person and a place is created and maintained (Arsel et al., 2012; Debenedetti et al., 2014; Rosenbaum, 2006), the role of place in consumer behavior studies is pushed to the background and relegated to merely being a research site. Treating place on as a research site neglects the role places play in consumer behavior, that means, for instance, how places shape and influence certain consumption practices and vice versa: For example, why and how Burning Man organizers transform a meaningless space (the middle of the desert) into a meaningful one (Kozinets, 2002)? Or how consumers create a place that allows for the 
non-monetary exchange of goods (Albinsson \& Perera, 2012) or for other ways of exchange (Belk, Wallendorf, \& Sherry, 1989)? The paper at hand explores why the creation of new places is necessary, and how a meaningless space might be transformed into a meaningful one.

\section{ANALYTICAL LENS: INSIGHT FROM HUMAN GEOGRAPHY}

In order to investigate the research questions, this paper turns to spatial theory as presented in the field of human geography. Spatial theory is based on the assumption that places are meaningful and constitute a fundamental aspect of human life (Tuan, 1971). Besides being a source of security and identity for individuals, places facilitate or prevent interaction, communication, or consumption activities. For instance, members of every household - often presented as a spatial entity separated from the outside world by walls - are expected to follow the idiosyncratic rules of the family. On a larger scale, places, and territories such as nations are subject to specific rules and norms. They moderate human behavior and are "understood as giving pace, variety and orientation to men" (Relph, 1976, p. 145). Places govern relations and tensions among objects (Kantor, 1993). Further, changes in society and the enactment of values only occur when a place that allows for such an enactment of values is produced (Lefebvre, 1991). Hence, places serve as a tool of thought and action (Lefebvre, 1991).

Places produce people, but are also produced by people. Human geography goes beyond the mere acceptance of the existence of places, enlightening us about the nature and the production of space. A place is easily distinguished from other places and its surroundings when it is identified or given a name. It might impart a "sense of place" (Seddon, 1972) - a feeling that people have for a specific place. For example, your home gets imbued with a specific meaning in comparison to the surrounding neighborhood. It has explicit and implicit rules that prevent undesired behavior and foster desired behavior. Hence, the nature of a place is the result of a socio-historical production process (Foucault \& Miskowiec, 1986; Lefebvre, 1991; Relph, 1976; Tuan, 1971). The geographical area formerly known as space is transformed into a place (Tuan, 1971). According to Relph (1976, pp. 28-43), places are meaningful spaces, that is, they attract and concentrate intentions, interactions, and 
communications of human beings. As such, places "are fusions of human and natural order and are the significant centers of our experience of the world" (Relph, 1976, p. 141). As a result of socio-historical production processes, places have their own idiosyncratic identity. This identity consists of three layers (Arsel et al., 2012; Relph, 1976; Rosenbaum, 2006): materiality, activities, and meaning.

These insights from human geography inform the findings insofar as they work with the assumption that every place is socio-historically constructed; includes materiality, activities, and meanings; and facilitates or prevents certain forms of interaction.

\section{CONTEXT}

This paper examines how activist consumers produce places. Through an ethnographic approach, the author immersed herself in the context of refugee helpers in Germany that create their own meaningful place. This place allows for meaningful interactions with the refugees.

At the end of August/beginning of September 2015, Germany unexpectedly received a wave of refugees. Despite a strong anti-refugee discourse (Brach, 2015), there was a huge wave of solidarity and support for the refugees (Jansen, 2015). The slogans "Refugees Welcome" or "Say it loud, Say it clear, Refugees are welcome here" exemplified the prevailing welcoming culture. People engaged in donations or other supporting activities in the form of voluntary helpers. These voluntary helpers sought ways of helping the arriving refugees and for displaying a welcoming culture to them. As state-run spots or camps struggled to welcome the masses of refugees in a warm way (Maurer, 2015), refugee helpers organized themselves and created their own places for interaction with the refugees.

This paper investigates a specific refugee initiative - one of several - designed to welcome the large numbers of refugees arriving into Germany. A group of refugee helpers noticed dozens of refugees sleeping on the floor without any supplies at the central bus station in a major German city. This bus station serves as a connecting point for refugees traveling to other countries or cities. Refugees often spend a couple of nights at the bus station before continuing to their desired destination. Calling themselves "Angels," these refugee helpers created a place that allowed 
them to provide refugees with food, clothing, and social interaction. The Angels described their mission in the following words:

We are a group of private individuals that distributes donated clothes, food, and drinks to refugees. With joy in our heart we want to accommodate refugees at the central bus station during their stopover. (https://www.facebook.com/groups/164076337265042/)

The Angels' place was located under a bridge and evolved from a foldable table into an assemblage of several large shipping containers that provide temporary accommodation, medical aid, and other necessities to the refugees. Support for refugees was provided from $6 \mathrm{pm}$ to midnight every day. The Angels welcomed up to approximately 90 refugees every evening at their place. Outside this timeframe there was no support for the refugees at the central bus station.

\section{METHODOLOGY}

Ethnographic data collection started in June 2015 (on-going) and includes participant observation, participation, and formal as well as informal interviews. As the author is immersed in this movement almost since its inception, this paper provides an emergent perspective on the creation of a place. Through intensive participation in the Refugees Welcome movement, continuous access to new informants was gained. The data set comprises 14 interviews with voluntary helpers. Open-ended interviews around their voluntary engagement and other consumption behavior were conducted at the informants' homes or cafes, depending on their preferences. All interviews were conducted face to face by the first author.

The interview guideline started with grand-tour questions to elicit the general background of the informants and to slowly familiarize them with the interview situation (McCracken, 1988). The guideline was designed to uncover details about participants' motivations, perceptions, and engagement within the Refugees Welcome movement. Interviews lasted from 32 to 122 minutes and were captured on digital audio files and transcribed verbatim. The total sample comprises in-depth interviews with 14 voluntary helpers, 56 pages of fieldnotes, as well as media coverage from two major German newspapers (65 articles).

Data analysis followed a hermeneutic approach and resulted in an iterative process of coding, theorizing, and collecting additional data (Arnold \& Fischer, 1994). The deep immersion of the first author in the life-world of 
voluntary helpers was crucial to achieve an in-depth understanding of the subject. The use of the hermeneutic circle included intra-textual analysis to establish individual narratives, and inter-textual analysis to contextualize the narratives.

\section{FINDINGS}

In the Findings section, this paper maps out why and how activist consumers produce a meaningful place in the form of a hyper-place. This paper defines hyper-place as a time-bounded place that is based on the ideals of caring and sharing - manifested through daily practices.

As refugee helpers struggle to enact the Refugees Welcome culture and the implied values and beliefs in official state-run places, they create their own place. Refugee helpers define a specific place by setting boundaries (spatial, personal, and access boundaries) that are embedded in the dynamics of demarcating and linking. The result is the transformation of a meaningless space into a meaningful place. This place allows for practices that combine materiality, activities, and meanings in new ways. It allows for the enactment and the transmitting of values (i.e., welcome culture) that are not accommodated in traditional marketplaces.

\section{Placelessness}

The arriving refugees are usually accommodated in state-run camps during their asylum application process. Often located outside of city centers - for instance, in abandoned office buildings - these camps set the refugees apart from the German population through cultural and spatial barriers. Those buildings are not meant to accommodate hundreds of refugees and are often quite derelict. For instance, some camps lack electricity or running water (Maurer, 2015). Personal space or privacy is rare, as up to 18 individuals live and sleep in a room of 25 square meters (fieldnotes). On officially being registered as a refugee, these people are allocated to a specific camp. This kind of setting does not allow for any privacy, is often temporary, interchangeable, and devoid of any meaning. As such, it resembles "placelessness" (Relph, 1976) - a word that is used to describe places that are devoid of meaning and perceived to be inauthentic. Foucault and Miskowiec (1986) describes something similar with the word heteropia: 
In general, the heterotopic site is not freely accessible like a public place. Either the entry is compulsory, as in the case of entering a barracks or a prison, or else the individual has to submit to rites and purifications. To get in one must have a certain permission and make certain gestures.

This definition captures the nature of refugee camps, where individuals have to undergo intensive screening and registration before being allowed to enter the place. Ironically, individuals who had to leave their own place are transferred to a place without soul or meaning. The camps are staterun but because of the unexpectedly large number of refugees, the camps rely heavily on voluntary refugee helpers. One of the informants explains her motivation to help. Says Andrea:

I want to give them security. At least temporarily. A feeling of security. The people that get here, they are traumatized, aircraft bombs, bombs, landmines. They are in permanent fear. I want to show them that Germany is a safe place and that they are welcomed. (Andrea)

Andrea wants to display a welcoming culture and to give refugees the feeling that they are accepted in Germany. However, those camps do not allow for such a welcoming culture. One of the informants captures the tension between state-run camps and the envisioned refugee welcome culture:

I want to welcome the refugees. But is this really the right way? They are set apart from the whole population. They are restricted in their behavior. And bored all day long. There is only administration. What are they supposed to think about Germany? (Lars)

In this quote Lars illustrates his fear that the accommodation in the state-camps is not able to convey the welcoming culture of the country. Refugees are set apart from German citizens, restricted in their movements as they are only allowed to dwell in this specific location, and have no distraction or leisure activities available to them. Lars describes the place as a mainly administrative camp that lacks human touch and empathy. Lars continues and explains the importance of conveying a welcome culture:

I remember my grandparents. After WWII, there were huge waves of migrations all over Germany. Especially with the East-West divide. My grandparents always tell stories when migrating somewhere. What they remember best is the help that was offered to them by strangers. Especially by the Americans that were occupying Berlin at this time. Never in their lives would they say something against the States. This is like a prevention of radicalization. (Lars)

For him, the welcome message is incredibly important because it shapes the first impression that refugees have of Germany. 
Similarly, Ingrid describes the tension between her own motivation and the prevailing conditions in state-run camps:

I wanted to help. Yes, those people need my help. So I went to the refugee camp (name). They are there for a week. I wanted to help. But instead, I was only waiting, waiting, waiting. Everything seemed so arbitrary. And it was unbearable. Germany is a rich country, but no running water for the refugees. I couldn't take it any longer. (Ingrid)

Ingrid was highly motivated to help and wanted to welcome the refugees. Instead, she experienced the partly inhumane conditions that prevail in such camps. She struggled with seeing people living under such conditions, which are a product of massive number of refugee arrivals that overburden available capacities. Voluntary helpers find it impossible to convey a welcoming message to refugees at such places. Furthermore, helping and volunteering is complicated and time-consuming as state-run camps are often located outside of city centers and voluntary refugee helpers are asked to sign up and undergo some training. To overcome these hurdles, the Angels created another place, which allowed them to convey the envisioned welcome culture. In the following I will outline how activist consumers created their own meaningful place through the dynamics of demarcating and linking.

\section{Creating Their Own Place through Setting Boundaries}

The Angels decided to create their own place as the existing places did not allow for the expression and communication of the Refugees Welcome mentality. Since places are located in space, they become distinguishable from other places by boundaries. In this way, they communicate with the surroundings (i.e., linking) and allow or prevent certain interactions (i.e., demarcation). The surroundings might be other actors in the marketplace as well as material factors (DeLanda, 2006; Deleuze \& Guattari, 1988).

This paper identifies three emergent themes during the coding process: spatial boundaries (location of the place), personal boundaries (the intersection of the place with the refugee helpers' lives), and access boundaries (who has the right to enter the place).

Spatial boundaries were negotiated in a sequential way. At the beginning, the Angels occupied, on a daily basis, a place at the central bus station where they set up a table for food distribution. After negotiations with the operator of the central bus station, they were given a more permanent 
place. However, this place was too small and they struggled to accommodate all the arriving refugees. The operator of the central bus station refused to allot them any more space. So, the Angels moved to a sidewalk under a bridge next to the central bus station. This sidewalk was the property of the city, and it was not put to use before, except for a few travelers crossing it. The Angels were tolerated here, and succeeded in creating a place with well-defined boundaries.

However, this place was not set apart from other places as it was located in the city center. Yet, it allowed for direct interaction between refugee helpers and refugees. Its centrality also meant that it was easily accessible to refugee helpers as well as to the refugees. The dynamics of demarcating and linking negotiate the spatial boundary of the place; the spatial boundaries define the place wherein refugees are welcome. Outside this safe confined space, a harsh reality awaits refugees. For instance, shop owners next to the Angels' place complain about the refugees and refuse to change money or even to sell them products.

Personal boundaries refer to the intersection of the Angels' place with the refugee helpers' personal lives. These boundaries are subject to an idiosyncratic negotiation process. Every individual has to define how far they want to insert themselves into the workings of the Angels' place. For some refugee helpers, it is enough just to distribute soup and hot beverages. Says Anika:

I just want to help. And what I like about it. I give them soup. Now. I give them tea.

Now. And I see their smile on their face. That is enough for me. (Anika)

This help without deep involvement or immersion is paid back to Anika through the refugees' smiles. Other helpers state more explicitly that they want to keep their distance. Says Ingrid:

I want to keep my distance. I have my own life. Yes, they need help. But I have my own life and I doubt that I am the right person for every form of help. (...) I would never accommodate refugees in my own home ... and yes, I have a spare room. (Ingrid)

For Ingrid, aiding refugees is specific to the Angels' place. It happens at a place that is set apart from her normal life and she does not desire any further interaction. Her goal is not to form an enduring attachment to refugees. Compare also Luisa who states that she would never give her personal phone number to refugees for further assistance or help. However, other refugee helpers take a more open approach and invite entire refugee families to their homes for a couple of days (fieldnotes). Overall, it is the 
refugee helpers who decide whether to integrate their voluntary work into their personal lives. Says Daphne:

I come here every evening. Directly after work. (...) Yes, it is exhausting. But I think it is the right thing to do. Those people need our help. And yes, I have to background other stuff, such as my applications for a new job. (Daphne)

Daphne prioritizes her work as a voluntary helper over her career. Instead of applying for a new job, she comes to the Angels' place every evening. By demarcating or linking the Angels' place to their personal lives, refugee helpers can decide how far they want to go with their involvement and immersion.

The third kind of boundary, access boundary, defines the accessibility of the place, that is, who is allowed to enter, communicate, and to interact with a specific place. In state-run camps, refugees have to register with the state before they receive any form of help or support. In contrast, the Angels offer unconditional help to the refugees. They do not check their registration status and supply everyone with food, drink, and clothes. For them, it is a form of humanitarian help. This humanitarian aid goes so far that is also includes homeless people. Says Maureen:

We do not make a distinction. When someone looks like he needs help, we help him. We help unconditionally. Refugees do not need to register. And we also help homeless people. They are in need. (Maureen)

Access is not restricted to registered refugees. On the contrary, the Angels' place is open to everyone who is in need of food, drink, clothes, or social interaction. The same is true of other actors who want to help. Says Caro:

We do not have any administration. Everything goes directly to the refugees. We do not lose time. And everyone just tries to do what they are able to do ... Everyone can participate or donate ... And you directly see the impact you have. (Caro)

Unlike state-run camps, the Angels have almost no administrative procedures. This lack of bureaucracy has two advantages. On the one hand, refugees directly benefit from the donated money. On the other hand, an absent bureaucracy allows different marketplace actors to participate. This is reflected in the diversity of actors that support the Angels' place. For instance, a street-kitchen supplies the Angels' place daily with fresh soup. An organization under the name of "Back-Up" collects discarded food items for the refugees; the professional services company PWC supplies the Angels with free food and drinks through their catering; Vapiano (a pizza chain) donates 30 pizzas every evening for the refugees; a free Internet 
connection creates a virtual space that enables refugees to communicate with their beloved ones at home. At the Angels' place everyone is welcome: every refugee and every person or company that wants to help in their own way.

Through boundary setting, the Angels created a distinct place. This place interacts with the larger spatial, cultural, and economic German frame through the defined boundaries. The boundaries of the Angels' place differ from state-run places - they are open to a degree that the place keeps a distinct identity while allowing for the maximum of interaction and participation. The primary goal is not to challenge existing state-run camps as often seen by activist consumers (Kozinets \& Handelman, 2004). Rather, the refugee helpers try to complement those places by offering something that cannot be offered in state-run camps, as those places do not allow for the conveying of a welcome message.

\section{Manifestation of a Welcome Culture}

As we have shown, the nature of the boundaries partly determines the place's identity as these boundaries restrict or enhance the interaction of the place with the surroundings. Practices that combine materiality, activities, and meanings (Arsel \& Bean, 2013) manifest and materialize the place identity. We describe in the following how refugee helpers and refugees co-created (Debenedetti et al., 2014; Rosenbaum, 2006) a welcoming culture through certain practices. These practices are different from those at state-run camps, although the mentality of refugee helpers is similar to that of officials at state-run camps: to offer assistance to people in need. This observation highlights the role of place for communication and interaction behavior. The idiosyncratic boundaries of a place allow for a place-specific demarcation or linkage regarding other actors in the marketplace. The boundaries influence the place identity, that is, materiality, activities, and meaning (Arsel et al., 2012; Relph, 1976; Rosenbaum, 2006). In the following, I illustrate how the identity of the Angels' place supports and prevents certain communication and interaction behavior.

The Angels' place was open for the participation and interaction of all and sundry. Even refugees that had arrived in Germany only three months ago worked as refugee helpers and took care of translations (fieldnotes). While in state-run camps, interaction between refugees and refugee helpers is often restricted to the distribution of food and beverages; the 
unconditional and open setting of the Angels' place however allows for other forms of interaction. Says Katharina:

Sometimes they get here as "dark" persons. Then you have to sit down. You talk to them. You listen to their stories. They tell you stories, over and over again. Then they start laughing about their own stories. The whole family starts laughing. They seem so happy to have finally someone that is listening to them. (Katharina)

Katharina welcomes the refugees through personal interaction. Similar to a psychotherapist, she temporarily releases the refugees from their traumatizing experiences. Singing and playing a guitar together were other practices that conveyed a welcoming culture.

The support provided is unconditional and surrounded by a sense of sharing and caring. At a desolate and usually abandoned place next to the central bus station, the Angels imbued a place with warmth. They created a place that allows for caring and sharing. Some fieldnotes of the first author highlight this impression:

\footnotetext{
The containers are standing in a dark spot of the central bus station. When approaching you see helpers in green jackets moving, supplying the refugees with food and beverages. It is cold outside. However, when approaching you get soaked in by a certain warmth. Umbrella heaters are heating up the outside space and suddenly you are surrounded by playing kids, people sitting together at tables and have a lot of thank yous and sparkles in their eyes when they can exchange their flip flops for some real winter boots. (fieldnotes)
}

A meaningless space got transformed into a place with a soul. Refugees seem to forget - at least temporarily - about their fate and are very grateful to the helpers.

The place's identity, defined through boundaries, also prevents certain practices. The place does not have the materiality to accommodate refugees at night. This is problematic, as refugees often have to wait until the next day for their bus. Says Caro:

\footnotetext{
Yes we want to help. But we also cannot do everything. We cannot provide dozens of refugees with a proper place to sleep. We do not have the available infrastructure. Not yet ... But until then, someone else has to take care of the refugees during the night time. (Caro)
}

Although they want to be caring, the refugee helpers lack the infrastructure to support such an activity. Their place is located in open air, except for a few containers that store some of their material. The Angels' place prevents such practices that are not essential for the objective of the refugee helpers: their goal is to deliver a good first impression and to convey a 
welcome culture. But they also accept their own boundaries: they cannot take care of the refugees in the long-term or even during nighttime.

Through these activities and practices, the refugee helpers create something that we call hyper-place. Similar to a hyper-community (Kozinets, 2002), the refugee helpers create a temporal place that is underpinned by the ideals of caring and sharing.

\section{DISCUSSION}

The findings highlight the role of places for the enactment of envisioned interactions and values. In the case of the refugee crises, the slogan Refugees Welcome is difficult to enact due to a lack of places that allow for such a meaningful communication. Similar to the Burning Man festival (Kozinets, 2002) or to "really really free markets" (Albinsson \& Perera, 2012), refugee helpers produce a meaningful place that allows them to express their values and their worldviews. By extending prior research, this research project shows that consumers do not necessarily strive to escape the market (Albinsson \& Perera, 2012; Kozinets, 2002) or to create a parallel market structure (Sandikci \& Ger, 2010), but try to complement it through unconditional aid. They represent a special form of consumer activism as they do not challenge existing structures (Kozinets \& Handelman, 2004) but add to them. This place might be seen as a form of micro-utopia (Foucault \& Miskowiec, 1986) with inversed rules and norms. This paper refers to it as a hyper-place. Analogous to the notion of hyper-community (Kozinets, 2002), it is a place that is only meant to exist for a certain period of time and stresses the ideas of caring and sharing. It is set apart from the official marketplace and governed by empathy and unconditional interactions (Kozinets, 2002).

With their place, refugee helpers pursue a specific purpose and, as such, they resemble a community of purpose (Schouten \& Martin, 2011): they rely heavily on social media for their organization, their boundaries are socially constructed, and the pay-out is not financial in nature.

The first author's in-depth immersion since the foundation of the Angels' place allows us to theorize on how places are produced by activist consumers (Arsel et al., 2012). Places do not exist in a sphere apart from the cultural sphere. Places are created for and created by consumers (Debenedetti et al., 2014) through the interplay with the cultural sphere or other actors in the marketplace. By drawing on spatial theory in human 
geography (Foucault \& Miskowiec, 1986; Lefebvre, 1991; Relph, 1976) this paper shows how such places might be constructed: through the negotiation of boundaries (spatial, personal, and access), activist consumers transform a meaningless space into a meaningful one. In this process, I highlight the role of materiality (Canniford \& Shankar, 2013; Epp, Schau, \& Price, 2014; Martin \& Schouten, 2014; Parmentier \& Fischer, 2014). Finally, this paper shows how a place prevents or fosters the enactment of certain practices that have the power to convey the desired welcoming culture.

\section{REFERENCES}

Albinsson, P., \& Perera, Y. (2012). Alternative marketplaces in the 21st century: Building community through sharing events. Journal of Consumer Behaviour, 11(4), 303-315.

Arnold, S. J., \& Eileen Fischer (1994). Hermeneutics and consumer research. Journal of Consumer Research, 21(1), 55-70.

Arsel, Z., \& Bean, P. (2013). Taste regimes and market-mediated practice. Journal of Consumer Research, 39(5), 899-917.

Belk, R. W., Wallendorf, M., \& Sherry, J. F. (1989). The sacred and the profane in consumer behavior: Theodicy on the odyssey. Journal of Consumer Research, 16(1), 1-38.

Brach, M. C. (2015). Wie Menschen zu Brandstiftern werden. Süddeutsche Zeitung.

Canniford, R., \& Shankar, A. (2013). Purifying practices: How consumers assemble romantic experiences of nature. Journal of Consumer Research, 39(5), 1051-1069.

Christian, D. L. (2003). Creating a life together: Practical tools to grow ecovillages and intentional communities. London: New Society Publishers.

Crockett, D., \& Wallendorf, A. (2004). The role of normative political ideology in consumer behavior. Journal of Consumer Research, 31(3), 511-528.

Debenedetti, A., Oppewal, H., \& Arsel, Z. (2014). Place attachment in commercial settings: A gift economy perspective. Journal of Consumer Research, 40(5), 904-923.

DeLanda, M. (2006). A new philosophy of society. London: Continuum.

Deleuze, G., \& Guattari, F. (1988). A thousand plateaus: Capitalism and schizophrenia. London: Bloomsbury Publishing.

Epp, A. M., Schau, H. J., \& Price, L. L. (2014). The role of brands and mediating technologies in assembling long-distance family practices. Journal of Marketing, 78(3), 81-101.

Foucault, M., \& Miskowiec, J. (1986). Of other spaces. Diacritics, 16(1), 22-27.

Fournier, S. (1998). Consumer resistance: Societal motivations, consumer manifestations, and implications in the marketing domain. Advances in Consumer Research, 25, 88-90.

Jansen, J. (2015). Ein freundliches, fröhliches Durcheinander. Frankfurter Allgemeine Zeitung.

Kantor, T. (1993). A journey through other spaces: Essays and manifestos, 1944-1990. Berkley, CA: University of California Press.

Karababa, E., \& Ger, G. (2011). Early modern ottoman coffeehouse culture and the formation of the consumer subject. Journal of Consumer Research, 37(5), 737-760.

Klein, J. G., Smith, N. C., \& John, A. (2004). Why we boycott: Consumer motivations for boycott participation. Journal of Marketing, 68(3), 92-109. 
Kozinets, R. V. (2002). Can consumers escape the market? Emancipatory illuminations from burning man. Journal of Consumer Research, 29(1), 20-38.

Kozinets, R. V., \& Handelman, J. M. (2004). Adversaries of consumption: Consumer movements, activism, and ideology. Journal of Consumer Research, 31(3), 691-704.

Lefebvre, H. (1991). The production of space. Oxford: Blackwell.

Luedicke, M. K., Thompson, C. J., \& Giesler, M. (2010). Consumer identity work as moral protagonism: How myth and ideology animate a brand mediated moral conflict. Journal of Consumer Research, 36(6), 1016-1032.

Martin, D. M., \& Schouten, J. W. (2014). Consumption-driven market emergence. Journal of Consumer Research, 40(5), 855-870.

Maurer, D. (2015). Tumult in überfüllter Mannheimer Flüchtlingsunterkunft. Focus.

McCracken, G. (1988). The long interview. London: Sage.

O'Guinn, T. C., \& Belk, R. W. (1989). Heaven at heritage on earth: Village, consumption USA. Journal of Consumer Research, 16(2), 227-238.

Parmentier, M.-A., \& Fischer, E. (2014). Things fall apart: The Dynamics of brand audience dissipation. Journal of Consumer Research, 41(5), 1228-1251.

Relph, E. (1976). Place and placelessness. London: Pion.

Rosenbaum, M. S. (2006). Exploring the social supportive role of third places in consumers' lives. Journal of Service Research, 9(1), 59-72.

Sandikci, Ö., \& Ger, G. (2010). Veiling in style: How does a stigmatized practice become fashionable? Journal of Consumer Research, 37(1), 15-36.

Schouten, J. W., \& Martin, D. M. (2011). Communities of purpose. In K. M. Ekström \& K. Glans (Eds.), Changing consumer roles - An anthology (pp. 125-136). London: Routledge.

Seddon, G. (1972). Sense of place. Perth: University of Western Australia Press.

Sherry, J. F. (2000). Place, technology, and representation. Journal of Consumer Research, 27(5), 273-278.

Tuan, Y.-F. (1971). Man and nature. Washington, DC: Association of American Geographers.

Üstüner, T., \& Holt, D. B. (2010). Toward a theory of status consumption in less industrialized countries. Journal of Consumer Research, 37(1), 37-56.

Zeynep, A., Debenedetti, A., \& Mérigot, P. (2012). The dynamics and continuity of place attachment: Cues from a parisian wine bar. In Z. Gürhan-Canli, C. Otnes, \& R. (J.). Zhu (Eds.), NA-Advances in consumer research (Vol. 40, pp. 28-31). Duluth, MN: Association for Consumer Research. 